\title{
Observing Consumer Market Changes from Brand Slogan Changes
}

\author{
Yang $\mathrm{Liu}^{1, *}$
}

\author{
${ }^{1}$ The Chinese University of Hong Kong \\ *liuyang199803@163.com
}

\begin{abstract}
The slogan of a brand is a summary of its product characteristics and brand connotation, and is one of the most important and effective ways for a brand to express itself in the market. A good slogan is the result of a deep insight into the consumer market, which allows consumers to quickly understand the unique selling points and connotations of the brand, and can even help the brand establish an emotional connection with consumers. This article analyzes the cases of brands changing slogans, figuring out the transformation of the consumer market is the external cause, and the brand's strategic deployment is the internal cause. The combination of external and internal causes caused these changes. By summarizing consumer market trend of rejuvenation, market sinking and higher requirements for product quality, this article gives some suggestions for brands to create and modify slogans.
\end{abstract}

\section{Keywords: brand slogan, brand strategy deployment, consumer market}

\section{INTRODUCTION}

In the commercial world, "a slogan is an integral component of a brand's advertising platform that helps shape its identity and define its positioning" [1]. It is also one of the most important and effective ways for brands to express themselves in the consumer market.

A good slogan is defined largely by the clarity of the message, the exposition of the benefits, rhymes, and creativity [1]. These are the results of profound insights into the consumer market. Companies usually have high expectations for their slogan, hoping that it can help differentiate their brand with others, provide customers with a reason to buy, or state a distinctive competency [2]. However, "advertisers indicate that the most important indicator of a slogan's effectiveness is recall" [2].

"Brand recall is the respondent's ability to remember the brand without any aid" [3]. Consumers' recall of brand slogan can greatly promote the generation of consumer behavior in consumption scenarios. Therefore, brands often invest a lot of publicity costs to increase the coverage and repetition of their slogans, so as to improve effects of brand recall [2].

The previous research on slogan focused on the evaluation of the effect of slogan and explored the factors that affect slogan recall. Since the recall of the slogan is so important to the brand, and the companies have also invested a lot of cost to promote their slogans, what cause the brands to change their slogans?

This article use the method of qualitative research, associating the brand slogan with the consumer market, and believes that the transformation of the consumer market is the external cause, and the brand's strategic deployment for the consumer market transformation is the internal cause. The combined effect of external and internal causes induces the change of a brand's slogan. This article connects slogans to consumer markets and can provide a practical reference for marketers. By analyzing the cases of brands that changed their slogans, we can summarize the characteristics and developmental direction of the consumer market, and propose suggestions for brands slogan adjustments.

\section{LITERATURE REVIEW}

\section{1.what is slogan?}

"A slogan is a short memorable phrase used in political, commercial, and clan, or even religious contexts as a repetitive expression with the goal of persuasion" [4]. In commercial world, scholars have no dispute over the definition of slogan. "Slogans are short, memorable phrases that are often used to sign off on advertisements." [1]. And the most important feature of slogan is its persuasiveness. 


\subsection{What is the role of slogan?}

"Together with brand name and logo, the slogan represents one of the three key elements of brand identity; that is, the elements by which the brand communicates with the world around it" [3]. In other words, slogan is a way for brands to show their brand image to consumers.

The roles of slogan can be divided into three aspects: express, distinguish and persuade.

First of all, slogan must clearly express the brand message to consumers. As the limitations of the brand name and logo, they lack the inherent ability to present much about the product. This is why brands need slogan, and they usually put slogan together with their names and logos [3]. Slogan must express to consumers what the product is, or the unique selling point of the product, or even what emotional benefit the product can bring to consumers. By doing this, slogan can help brands increase their awareness.

Secondly, by building up brand image, slogan can help a brand to distinguish itself from other competing brands. Especially in the fierce market competition, distinguishing from other competitors is conducive to the development of the brand.

Finally, the effect of slogan should be based on persuasion to promote the generation of consumers' purchase intention and consumption behavior. Slogan can produce a recall effect in the minds of consumers by conveying brand information and establishing a brand image. When consumers need to buy a certain category of products, recall can often play a role, prompting the generation of intentional purchase behavior.

\subsection{Why some brands have changed their slogans?}

High spending, i.e. repetition and regularity is the way to make consumers recall a brand's slogan. In such a case, the slogan has to be retained rather than changed over time [5]. But in the real market competition, there are indeed many examples of brands changing their slogans. Why?

The consumer market is a huge and complex system. Regardless of age, gender, or occupation, everyone in modern society is a member of the consumer market. In other words, the consumer market is a collection of consumers with various background.

Because the consumer market is affected by many factors such as economy, culture, society, and geography, it is in a dynamic state of change. While the rapid development of economy and the Internet has accelerated changes of the consumer market, as well as its diversified development. As a brand oriented to the consumer market, only by adjusting its strategic deployment in accordance with the ever-changing consumer market can it maintain a place in the fierce market competition. Slogan is the brand's selfexpression in the consumer market, and it is also the embodiment of the brand's strategic deployment. Timely adjustment of slogan will help the brand maintain its attractiveness to consumers.

For example, in the Q3 quarter of 2020, the chocolate brand Dove changed slogan from "enjoy silky" to "choose pleasure". I have to say that this is a very smart strategy. Although the previous slogan has been well-known by the public, and has a great coverage and spread on social media, many netizens even turned it into a popular Internet phrase used to describe other things that are very smooth. This helped the brand cultivate a large number of loyal customers. However, as a snack brand, Dove's previous target consumer groups have reduced demand for snack products due to changes in age and awareness of healthy living habits. If Dove does not make strategic adjustments, it may face the consequences of consumer loss. Attracting new and young consumer groups is the first step in solving this problem. Because young consumers grew up in an environment with developed Internet and sufficient material, they have shown obvious different characteristics in terms of lifestyle and consumption habits. They pay more attention to the good experience and spiritual satisfaction brought by consumption. Therefore, the brand slogan has changed from focusing on the functional benefit of taste to emphasizing the benefit of emotional satisfaction. In addition, since the main consumers of chocolate products are women, in view of the general environment that promotes gender equality, Dove encourages women to pursue a pleasant lifestyle through the new slogan, which is beneficial for the brand harvesting a wave of user favorability and helping the brand cultivate customers stickiness.

A similar case is Taobao. At the end of August this year, Taobao announced that its brand slogan was changed from "shopping anytime, anywhere you want" to "the shopping experience is so great". The new slogan starts from the consumer's standpoint, and puts more emphasis on the use experience that Taobao brings to consumers, and meets the needs of young consumers for spiritual satisfaction brought about by consumption. At the same time, the new slogan is more colloquial and more grounded in expression. Although the colloquial slogan is more conducive to consumer recall, it is clear that Taobao has deeper considerations. Meanwhile, another online shopping platform Pinduoduo, which is very similar to Taobao's business model, entered the market. However, Pinduoduo focuses on consumer groups in the third and fourth tier markets and pays more attention to market sinking. Therefore, the rise of Pinduoduo has snatched Taobao's mid- and low-end markets and caused a great threat to Taobao. With the development of the economy, the consumption intention 
and spending power of consumers in third- and fourthtier cities have risen sharply. At the same time, the epidemic has greatly deepened consumers' online shopping habits. Therefore, Taobao had to compete head-on with Pinduoduo, and made a series of strategic adjustments, including " tens of billions of subsidies", "discount every day" and other preferential activities, as far as possible to direct consumers' attention to the lowend products, in order to seize the low-end market. Changing the slogan is also part of Taobao's strategy of sinking the market, because the more colloquial slogan is easier to be accepted and loved by consumers in the low-end consumer market.

We can also see Youku's future strategic layout from Youku's new slogan. In September this year, Youku changed its slogan from "this world is so cool" to "what you love to watch is on the air". It is not difficult to know that Youku will concentrate its resources in the future to create high-quality content based on the preferences of young consumer groups. The video industry has a large number of users and fierce market competition. The content advantages of other platforms such as IQIYI and Tencent have led to Youku's dilemma to some extent. The homogeneity and vulgarity of video content have led to the tiredness of young consumer groups. The video industry has entered a new period where "content is king" works. It can be said that who can produce high-quality content that young consumers love, then they can win this competition. Therefore, Youku's new slogan is definitely telling consumers that Youku knows what they like and can provide them with high-quality content.

\section{CONCLUSION}

\subsection{The connection between slogan and consumer market}

This is the consensus of researchers and marketers that slogan is very important for the development of the brand. Based on the analysis of a brand's behavior in changing its slogan, we can summarize the characteristics and developmental direction of the current consumer market.

First of all, as the spending power of young consumer groups rises, they have become the main force in the consumer market, and brands in different industries have to make strategic adjustments to attract their attention. Strategic adjustment should be a response of insight into consumers' psychology, otherwise the adjustment will be ineffective. While the young consumer group grew up in the Internet era and shows significantly different characteristics from other age groups in many aspects. Therefore, brands have to analyze the consumption behavior and consumption habits of young consumers. The focus of young consumers on products is no longer only on the functional level. Young consumers are also eager to fulfill their emotional needs by purchasing products, that is, to build emotional resonance with the brand. By purchasing products of a certain brand, consumers can show their personality, preferences and even lifestyle.

The second is the rise of consumption power in the middle and low-end markets, and the huge market space will inevitably lead to fierce market competition. When capital is pouring into this track, whoever can have a deep insight into this group will have the opportunity to attract more consumers.

Finally, consumers have high requirements for product quality. Whether in the short video industries or other industries, when the market supply exceeds demand, the quality of products or services becomes particularly important. Therefore, when companies strive to establish emotional connections with consumers, they must ensure the high quality of their products. This is the basis for market competition.

\section{2. suggestions}

Based on the analysis of new changes in the consumer market, in the future, if a brand has plans to change slogan or a new brand needs to propose a slogan, you can refer to the following suggestions:

First of all, clear positioning and expression of the brand product itself, including the unique selling point of the product, slogan's target audience, product competitors, etc. The insight into the brand product itself is the foundation of everything.

What is unique about your product compared to your competitors' products? Why should consumers buy your product and not your competitor's? These are the messages that brands need to tell consumers. "Every slogan is a brand positioning tool, and it should position the brand in a clear manner." The prerequisite for achieving this goal is to know "where you are and, more importantly, where you are going"[3].

Secondly, enterprises should have deep insights into target consumers. You have to understand the identity, occupation, age, consumption preferences, living habits, media contact habits, etc. of your target consumers. When you put yourself in the same position as your target consumers, you will find out what they need and what they like. Only in this way can you come up with a slogan that can establish an emotional connection with consumers.

This has the prerequisite that the brand must target its target audience precisely. Almost no product can appeal to all consumers, so smart brands began to segment the market. Communicating only to the target consumers not only saves advertising costs, but can also make it more effective. 
Finally, use a variety of ways to help consumers have a better recall effect on your slogan, including but not limited to good creativity, colloquial, rhyming and other forms. This is why many brands have a very simple and powerful slogan, which is easy to remember.

You need to let your target consumers notice your slogan first, then recognize the connotation conveyed by your slogan, then remember your slogan, and finally achieve the effect of recall. Consumers' recall of your slogan may be transformed into their consuming behavior in consumer scenarios.

\section{REFERENCES}

[1] Mayukh Dass, Chiranjeev Kohli, Piyush Kumar, Sunil Thomas. A study of the antecedents of slogan liking[J]. Journal of Business Research, 2014, 67(12):

[2] Elten Briggs, Narayan Janakiraman. Slogan recall effects on marketplace behaviors: The roles of external search and brand assessment[J]. Journal of Business Research,2017,80:

[3] Chiranjeev Kohli, Lance Leuthesser, Rajneesh Suri. Got slogan? Guidelines for creating effective slogans[J]. Business Horizons, 2007,50(5):

[4] Safavi Sarvenaz. Bühler's organon model of communication: a semiotic analysis of advertising slogans[J]. Semiotica, 2021, 2021(242):

[5] Maria Rybaczewska, Siriphat Jirapathomsakul, Yiduo Liu, Wai Tsing Chow, Mai Thanh Nguyen, Leigh Sparks. Slogans, brands and purchase behaviour of students[J]. Young Consumers, 2020, 21(3):

[6] Wesseloo D M. The reflection of core values in a company's logo and slogan - An experimental study. 2015. 